\title{
Fabrication and characteristics of nitrogen-doped nanocrystalline diamond/p-type silicon heterojunction
}

\author{
D. Lu, H. D. Li*, S. H. Cheng, J. J. Yuan and X. Y. Lv
}

Nitrogen-doped nanocrystalline diamond films (N-NDFs) have been deposited on p-type silicon (Si) by microwave plasma chemical vapor deposition. The reaction gases are methane, hydrogen, and nitrogen without the conventional argon (Ar). The N-NDFs were characterized by X-ray diffraction, Raman spectroscopy, and scanning electron microscopy. The grain sizes are of $8 \sim 10 \mathrm{~nm}$ in dimension. The N-NDF shows n-type behavior and the corresponding N-NDF/p-Si heterojunction diodes are realized with a high rectification ratio of $10^{2}$ at $\sim 7.8 \mathrm{~V}$, and the current density reaches to $1.35 \mathrm{~A} / \mathrm{cm}^{2}$ at forward voltage of $8.5 \mathrm{~V}$. The findings suggest that fabricated by $\mathrm{CH}_{4} / \mathrm{H}_{2} / \mathrm{N}_{2}$ without Ar, the N-NDFs and the related rectifying diodes are favorable for achieving high performance diamond-based optoelectronic devices.

Keywords: Nanocrystalline diamond film; Chemical vapor deposition; Nitrogen doped; Heterojunction diodes; Current-voltage characteristics

Citation: D. Lu, H. D. Li, S. H. Cheng, J. J. Yuan and X. Y. Lv, "Fabrication and characteristics of nitrogen-doped nanocrystalline diamond/p-type silicon heterojunction", Nano-Micro Lett. 2, $56-59$ (2010). doi:10.5101/nml. $\underline{\mathrm{v} 2 \mathrm{i} 1 . \mathrm{p} 56-59}$

Diamond is an important semiconductor for high-power and high-temperature electronic devices because of its large band gap $(5.47 \mathrm{eV})$ and high thermal conductivity $(20 \mathrm{~W} / \mathrm{cm} \cdot \mathrm{K})$. The realizations of p-type and n-type diamonds by chemical vapor deposition (CVD) are desirable for the applications of diamond-based electronic devices. A p-type diamond can be easily achieved by introducing boron dopant [1], while it is difficult to obtain effective n-type diamond due to the formation of deep donor levels with a large activation energy (e.g., $1.7 \mathrm{eV}$ for nitrogen $\left(\mathrm{N}_{2}\right)$ doping in bulk diamond [2]) or low doping efficiency (e.g., the compensation ratio reaches to as high as around 50 90\% in the phosphorus-doped (001) diamond [3]). Recently, CVD nanocrystalline diamond films (NDFs) have been paid more attentions due to their facile doping, high density of grain boundaries, increased $\mathrm{sp}^{2}$-carbon bonded content and smooth surface, which lead to numerous optoelectronic and mechanical applications [4]. It was reported that n-type conductivity has been easily realized in the N-NDFs, since the $\mathrm{N}$-atoms present predominantly in grain boundaries and introduce new electronic states associated with carbon $\pi$ bonds and dangling bonds in the fundamental band gap [5]. The N-NDFs were generally prepared by introducing nitrogen $\left(\mathrm{N}_{2}\right)$ in the $\mathrm{Ar} / \mathrm{CH}_{4} / \mathrm{H}_{2}$ [6] or $\mathrm{Ar} / \mathrm{CH}_{4}$ [7] source gases. In these cases, $\mathrm{N}_{2}$ is proposed as the n-type dopant, and $\mathrm{Ar}$ is favorable for generating more $\mathrm{C}_{2}$ radical precursors to increase the nucleation density and consequently decrease the grain size to nanometer scale. In fact, N-NDFs can also be deposited by CVD without introducing $\mathrm{Ar}$ in reaction ambient [9]. There are two advantages for the fabrication process without Ar, on the one hand, the experimental conditions are simplified; on the other hand, the possible negative effects of $\mathrm{Ar}$ ions on the devices would be reduced. It is therefore desirable to further investigate the properties of NDFs prepared by $\mathrm{H}_{2} / \mathrm{CH}_{4} / \mathrm{N}_{2}$ and the corresponding applications in optoelectronic devices.

In this paper, we report the growth of N-NDFs by microwave plasma CVD (MPCVD) with the reaction gases of $\mathrm{H}_{2} / \mathrm{CH}_{4} / \mathrm{N}_{2}$. The products consist of diamond-phase-rich grains with an average size of $\sim 8 \mathrm{~nm}$. Deposited on p-type silicon ( $\mathrm{Si}$ ), the $\mathrm{N}-\mathrm{NDF} / \mathrm{p}-\mathrm{Si}$ heterojunction diodes are realized showing the typical rectifying behavior. The devices have high rectification ratio and large forward current density with a low reverse leakage current.

The N-NDFs were grown by MPCVD system (with AsTeX-1500, $2.45 \mathrm{GHz}$ ) using the gas mixture of $\mathrm{H}_{2} / \mathrm{CH}_{4} / \mathrm{N}_{2}$ 
with the flow rate ratio of $110 / 10 / 30$ in sccm. The p-type (111) Si (conductivity: $\quad 0.05 \sim 0.1 \quad \Omega^{-1} \cdot \mathrm{cm}^{-1}$ ) substrate was first mechanically abraded with $0.2 \mu \mathrm{m}$ diamond powders for $10 \mathrm{~min}$, and then was ultrasonically seeded for $30 \mathrm{~min}$ in diamond slurry consisting of nano/micro-diamond powders to enhance the nucleation density. Finally, the substrate was cleaned ultrasonically in alcohol and acetone for $5 \mathrm{~min}$. In the deposition process, the applied microwave power and total reaction gas pressure was $250 \mathrm{~W}$ and $6.7 \mathrm{kPa}$. The substrate temperature was kept at about $900^{\circ} \mathrm{C}$ measured by a two-color infrared ratio thermometer (CHINO, Mode IR-GZ201N). The deposition time was $4 \mathrm{~h}$.

The structure and morphology of the as-synthesized N-NDFs were characterized by means of Raman spectroscopy (Renishaw inVia, excitation wavelength of $514.5 \mathrm{~nm}$ ), X-ray diffraction (XRD, Rigaku D/max-rA with $\mathrm{Cu} \mathrm{K \alpha}$ radiation) and scanning electron microscopy (SEM, JSM-6700F). Optical emission spectroscopy (OES, by Ocean Optics USB4000) was used to measure the species in the $\mathrm{CH}_{4} / \mathrm{H}_{2} / \mathrm{N}_{2}$ plasma. For the electrical measurements of the devices, the silver (Ag) slurry was used as the contacts on the surface of N-NDFs and backside of p-type Si. In order to achieve ohmic contact, the devices were subjected to thermal annealing process at $150^{\circ} \mathrm{C}$ for $15 \mathrm{~min}$ in air. The current voltage (I-V) curves were measured using Keithley sourcemeter 2400 by the two-point probe method. All the examinations were performed at room temperature.

Figure 1(a) shows the SEM image of the N-NDF. The film consists of nanosized grains, which is similar to that deposited in Ar-rich $\mathrm{H}_{2} / \mathrm{CH}_{4} / \mathrm{N}_{2}$ ambient $[6,7,10]$. Observed from the high magnification image (the inset of Fig. 1), the grains are of $8 \sim 10$ $\mathrm{nm}$ in dimension, and the major grains are aggregated. The surface of the film is relatively loose. The thickness of the
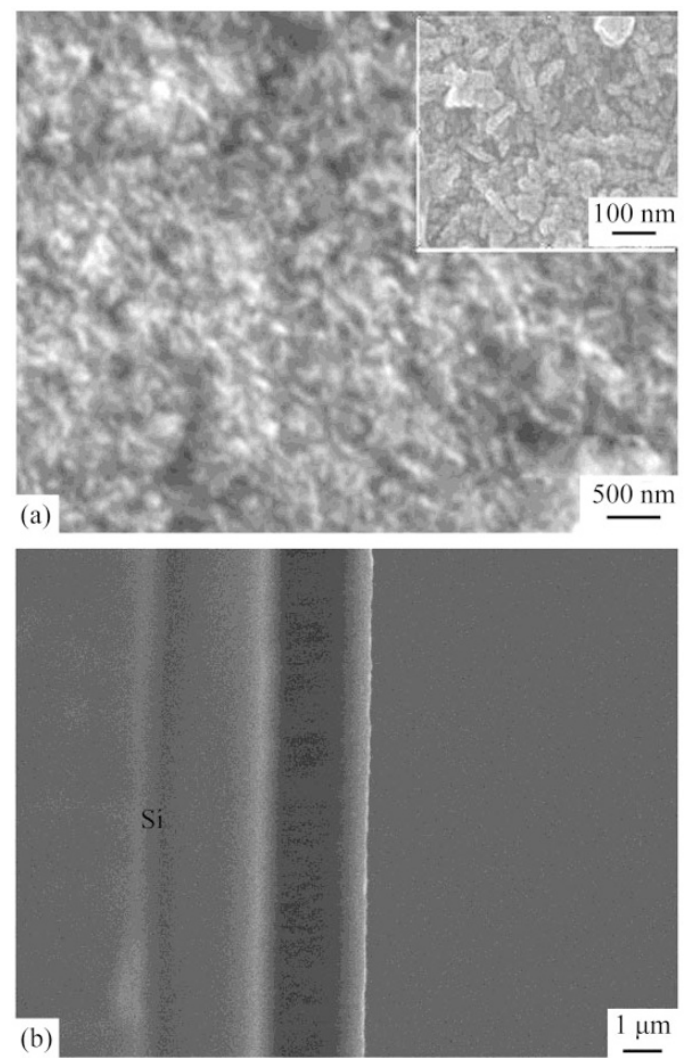

FIG. 1. (a) SEM image of the N-NDF and the inset is the high magnification image, (b) the cross-section SEM image of the N-NDF. as-grown N-NDF is about $2.8 \mu \mathrm{m}$, estimated from the cross-section SEM image shown in Fig. 1(b), and the growth rate is estimated to be about $0.7 \mu \mathrm{m} / \mathrm{h}$. The OES spectra with different $\mathrm{N}_{2}$ flow rate are shown in Fig. 2. In the $\mathrm{H}_{2} / \mathrm{CH}_{4} / \mathrm{N}_{2}$ plasma, the $\mathrm{CN}$ violet emission (at $387.4 \mathrm{~nm}$ and $418.9 \mathrm{~nm}$ ), hydrogen emission ( $\mathrm{H} \alpha$ at $656.5 \mathrm{~nm}, \mathrm{H}_{\beta}$ at $486 \mathrm{~nm}$ ) and $\mathrm{C}_{2} \mathrm{Swan}$ band (at $516.2 \mathrm{~nm}$ ) are observed [11]. Compared with Ar-rich plasma [12] that the $\mathrm{C}_{2}$ dimers are dominant, the $\mathrm{CN}$ species show the strongest intensity in the $\mathrm{CH}_{4} / \mathrm{H}_{2} / \mathrm{N}_{2}$ plasma and the $\mathrm{C}_{2}$ dimers intensity is very low. As the $\mathrm{N}_{2}$ flow rate increased from $10 \mathrm{sccm}$ to $30 \mathrm{sccm}$, the relative intensity of $\mathrm{CN} / \mathrm{H} \alpha$ enhanced. Although the $\mathrm{CN}$ species do not lead to diamond growth by themselves, the large amount of $\mathrm{CN}$ species will be favorable for the formation of more defects and result in the decrease of grain

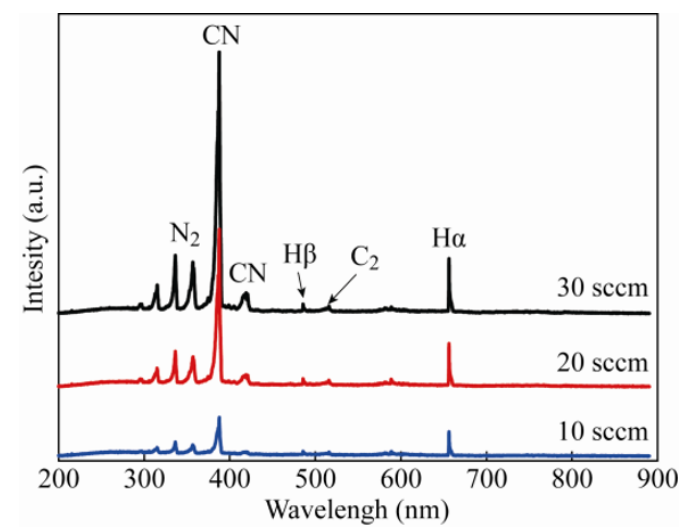

FIG. 2. OES spectra of the $\mathrm{CH}_{4} / \mathrm{H}_{2} / \mathrm{N}_{2}$ plasma with $\mathrm{N}_{2}$ flow rate from $10 \mathrm{sccm}$ to $30 \mathrm{sccm}$.

size in NDFs [13].

The typical XRD pattern of the N-NDF is shown in Fig. 3(a). The peaks at $43.9^{\circ}$ and $75.6^{\circ}$ are assigned to diamond (111) and (220) diffractions, respectively. The average grain size (d) is obtained by Sherer's formula [14]: $d=0.9 \lambda / B \cos \theta$, where $\lambda=$ $1.54016 \AA$ and $\mathrm{B}$ is the full width at half maximum (FWHM) of the diffraction peak. The average crystal size calculated from (111) peak is about $8.6 \mathrm{~nm}$, which is in consistence with the size observed in SEM image (see Fig. 1).

Figure 3(b) shows the Raman spectrum of the sample. The peak at $1333 \mathrm{~cm}^{-1}$ is assigned to the intrinsic zone-centre phonon band of diamond. The broad bands centered at about $1360 \mathrm{~cm}^{-1}$ and $1555 \mathrm{~cm}^{-1}$ are attributed to the disordered $\mathrm{D}$ band and graphitic $\mathrm{G}$ band especially related to nanocrystalline diamond (NCD), respectively $[6,15,16]$. The nitrogen presence in the lattices of N-NCD is demonstrated by the blue shift of $1360 \mathrm{~cm}^{-1}$ band from the D band $\left(1340 \mathrm{~cm}^{-1}\right)$ of undoped NCD [15]. Note that there is a shoulder band appearing at about $1150 \mathrm{~cm}^{-1}$, though its origination is still debated. It was previously proposed as a characteristic Raman spectral feature for NCD [17-19]. However, some researchers $[15,20]$ pointed out that the peak should not be attributed to the presence of NCD and/or other sp3-bonded phases, but to trans-polyacetylene segments existing in the grain boundaries. Nevertheless, combined with the above XRD and SEM results, the synthesized products consist mainly of nanosized diamond crystals.

Figure 4(a) and 4(b) show the I-V characteristics of Ag contacts on p-typed $\mathrm{Si}$ and N-NDF, respectively. It is found that the observed $\mathrm{I}-\mathrm{V}$ behaviors are linear for both forward and reverse bias, suggesting that ohmic contacts have been formed 

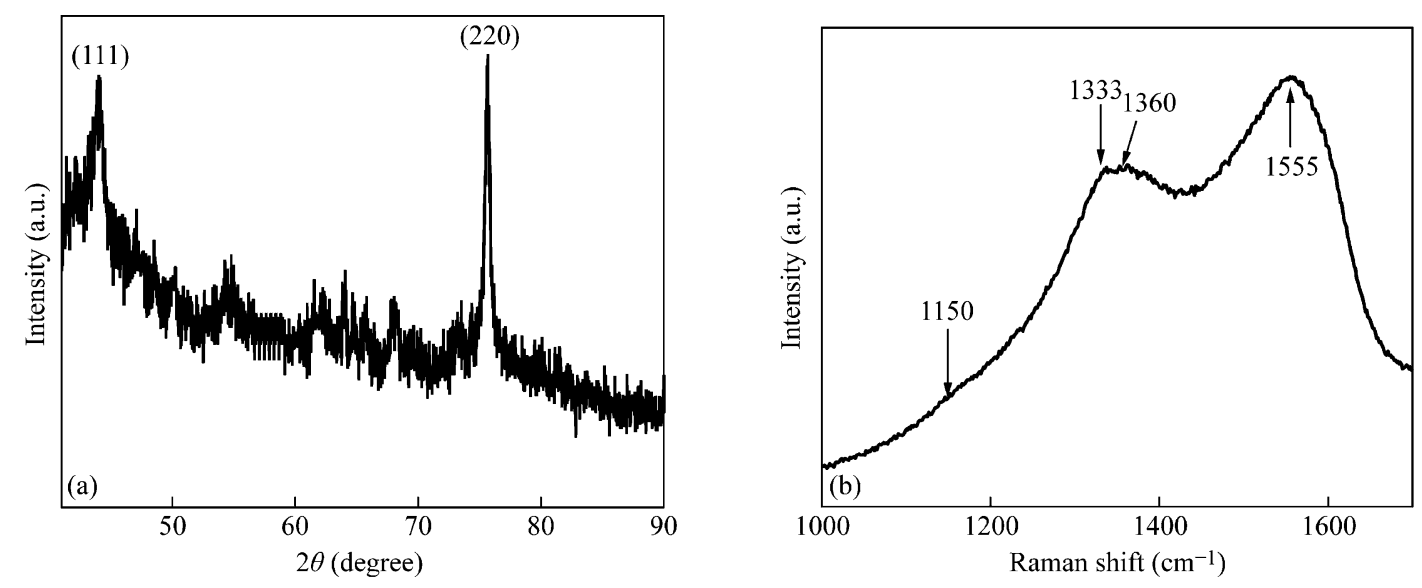

FIG. 3. (a) XRD pattern and (b) Raman spectrum of the N-NDF.
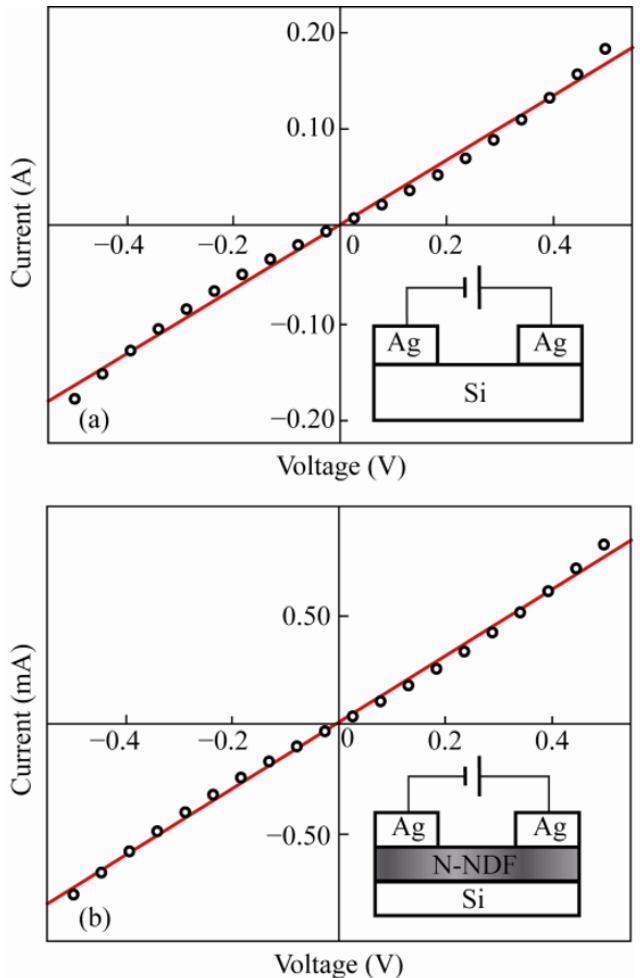

FIG. 4. I- $V$ characteristics for the interface of (a) $\mathrm{Ag} / \mathrm{p}$-type $\mathrm{Si}$ and (b) $\mathrm{Ag} / \mathrm{n}$-type NDF.

between $\mathrm{Ag} / \mathrm{Si}$ and $\mathrm{Ag} / \mathrm{N}-\mathrm{NDF}$. Note that the current intensity of $\mathrm{Ag} / \mathrm{Si}$ is about 200 times higher than $\mathrm{Ag} / \mathrm{N}-\mathrm{NDF}$, indicating that the N-NDF possesses higher resistivity with respect to $\mathrm{Si}$. The resistivity of as-deposited N-NDF is about $10^{5} \Omega \cdot \mathrm{cm}$, calculated by the following equation [9]

$$
\rho_{D}=\left(R-\rho_{S} L_{S} / A\right) A / L_{D}
$$

where $\mathrm{R}$ is the total resistance (silicon substrate and NDF) obtained from I-V measurement $\left(\sim 10^{3} \Omega \cdot \mathrm{cm}\right)$, A is the area of the electrode $\left(\sim 5 \mathrm{~mm}^{2}\right), \rho_{\mathrm{S}}$ is the resistivity of silicon substrate $(10 \Omega \cdot \mathrm{cm})$, and $\mathrm{L}_{\mathrm{S}}$ and $\mathrm{L}_{\mathrm{D}}$ are the thickness of silicon substrate $(500 \mu \mathrm{m})$ and NDF $(\sim 2.8 \mu \mathrm{m})$ measured from the SEM cross-sectional images, respectively.

The typical current-voltage curve of the N-NDF/p-Si heterojunction diode is shown in Fig. 5. The rectification characteristic is represented with rectification ratios up to $10^{2}$ orders of magnitude at $\sim 7.8 \mathrm{~V}$. The rectifying result suggests that

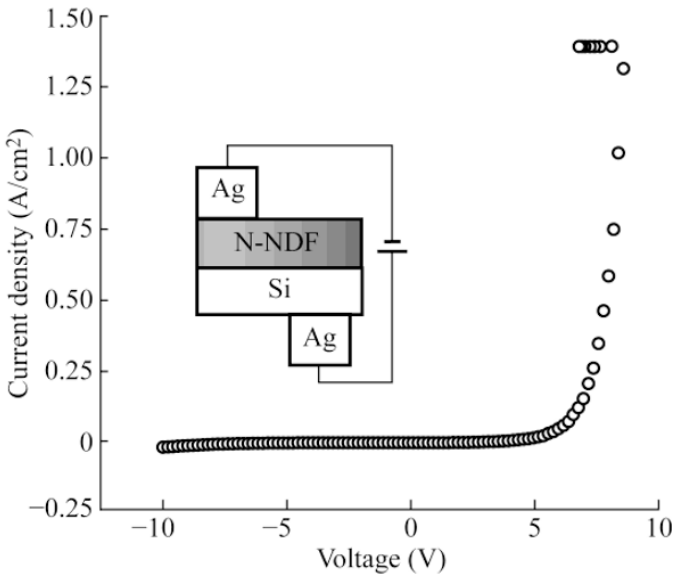

FIG. 5. $I-V$ characteristic of the n-NDF/p-Si heterojunction diode.

the major carriers for the N-NDF are electrons, i.e., the N-NDF might show n-type characteristic. The turn-on voltage of the heterojunction is about $4.8 \mathrm{~V}$, and the current density can achieve to $1.35 \mathrm{~A} / \mathrm{cm}^{2}$ at a forward bias of $8.5 \mathrm{~V}$. These data are comparable with that obtained from the case of N-NDF fabricated in the system of $\mathrm{Ar} / \mathrm{CH}_{4} / \mathrm{N}_{2}$ [8]. Moreover, when the reverse-bias increases as high as $\sim 10 \mathrm{~V}$, the leakage current is small $\left(\sim 0.015 \mathrm{~A} / \mathrm{cm}^{2}\right)$, which can be related to the low conductivity $\left(<10^{-5} \Omega^{-1} \cdot \mathrm{cm}^{-1}\right)$ of the N-NDF measured by the Van der Pauw method. The high resistivity is proposed to be attributed to the loose feature represented in the N-NDF (see Fig. 1). In addition, for the NDFs grown in the $\mathrm{H}_{2}$-rich plasma of $\mathrm{CH}_{4} / \mathrm{H}_{2} / \mathrm{N}_{2}$, the hydrogen atoms can easily bind with the unpaired electrons of the doped nitrogen atoms, resulting in a lower electrical conductivity [21]. Interestingly, it is found that no saturation trend appears for the forward current at $\sim 9 \mathrm{~V}$, implying that the current can reach higher value with the increase of forward voltage, leading to higher rectification ratio. Due to the current limit of the test equipment, the experiments performed at high forward voltages $(>10 \mathrm{~V})$ were not carried out.

$\mathrm{Ma}[9,13]$ mentioned that the increasing concentration of $\mathrm{CN}$ species may be the reason for the formation of ordered $\mathrm{sp}^{2}$-bond carbon and thus decrease the film resistivity from $10^{9}$ to $10^{5}$ $\Omega \cdot \mathrm{cm}$ which is still higher than the Ar- rich plasma prepared films. In the NDFs deposited by $\mathrm{CH}_{4} / \mathrm{H}_{2} / \mathrm{N}_{2}$ plasma, the adding of $\mathrm{N}_{2}$ introduces few new electronic states in the band gap. However, new states exist in the NDFs prepared by Ar- rich plasma through the theoretical prediction $[5,22]$. Due to less 
mid-gap states in our N-NDF, the interfacial barrier potential in the NDF/Si interface is higher than samples of the Ar-rich plasma [8]. The high interfacial barrier potential may be the main reason for the high turn-on voltage $(\sim 4.8 \mathrm{~V})$. Meanwhile, the less new defect states near the Fermi level regarded as leakage current source [8] in our specimen is beneficial for achieving a comparatively small leakage current $\left(\sim 0.015 \mathrm{~A} / \mathrm{cm}^{2}\right.$ at $\left.10 \mathrm{~V}\right)$ in the N-NDF/p-Si heterojunction.

In summary, the growth and characterization of the N-NDF deposited by MWCVD in $\mathrm{N}_{2} / \mathrm{CH}_{4} / \mathrm{H}_{2}$ are reported. The $\mathrm{N}-\mathrm{NDF} / \mathrm{p}-\mathrm{Si}$ heterojunction diodes have been achieved having high rectification ratio of $10^{2}$ and high current density (1.35 $\mathrm{A} / \mathrm{cm}^{2}$ at forward bias of $8.5 \mathrm{~V}$ ) with low leakage reverse current. It is demonstrated that the N-NDFs fabricated without the conventional Ar can also be used to realize high performance diamond-based optoelectronic devices.

This work was financially supported by the Programs for New Century Excellent Talents in University (NCET, No. 06-0303) and the National Natural Science Foundation of China (NSFC, No. 50772041).

\section{Received 14 March 2010; accepted 23 March 2010; published online 8 April 2010.}

\section{References}

1. R. Kalish, Carbon 37, 781 (1999). doi:10.1016/S00086223(98)00270-X.

2. P. K. Sitch, G. Jungnickel, M. Kaukonen, D. Porezag, Th. Frauenheim, M. R. Pederson and K. A. Jackson, J. Appl. Phys. 83, 9 (1998). doi:10.1063/1.367249

3. H. Kato, S.Yamasaki and H. Okushi, Diamond Relat. Mater. 16, 796 (2007). doi:10.1016/j.diamond.2006. $\underline{11.085}$

4. K. Subramanian, W. P. Kang and J. L. Davidson, Proceeding 18th IVNC, 198 (2005).

5. P. Zapol, M. Sternberg, L. A. Curtiss, T. Frauenheim and D. M. Gruen, Phys. Rev. B 65, 045403 (2001). doi:10.1103/ PhysRevB.65.045403

6. Q. Hu, M. Hirai, R. K. Joshi and A. Kumar, J. Phys. D: Appl. Phys. 42, 025301 (2009).
7. S. Bhattacharyya, O. Auciello, J. Birrell, J. A. Carlisle, L.A. Curtiss, A. N. Goyette, D. M. Gruen, A.R. Krauss, J. Schlueter, A. Sumant and P. Zapol, Appl. Phys. Lett. 79, 1441 (2001). doi:10.1063/1.1400761

8. T. Ikeda and K. Teii, Appl. Phys. Lett. 94, 072104 (2009). doi:10.1063/1.3082045

9. K. L. Ma, W. J. Zhang, Y. S. Zou, Y. M. Chong, K. M. Leung, I. Bello and S.T. Lee, Diamond Relat. Mater. 15, 626 (2006). doi:10.1016/j.diamond.2005.11.017

10. T. D. Corrigan, D. M. Gruen, A. R. Krauss, P. Zapol and R. P. H. Chang, Diamond Relat. Mater. 11, 43 (2002). doi:10.1016/S0925-9635(01)00517-9

11. T. Vandevelde, M. Nesladek, C. Quaeyhaegens and L. Stals, Thin Solid Films 290, 143 (1999). doi:10.1016/ S0040-6090(96)09189-4

12. Y. K. Liu, P. L. Tso, D. Pradhan, I. N. Lin, M. Clark and Y. Tzeng, Diamond Relat. Mater. 14, 2059 (2005). doi:10.1016/j.diamond.2005.06.012

13. K. L. Ma, J. X. Tang, Y. S. Zou, Q. Ye, W. J. Zhang and S. T. Lee, Appl. Phys. Lett. 90, 092105 (2007). doi:10.1063/ 1.2709953

14. B. D. Cullity, Elements of X-Ray Diffraction (Addison-Wesley, Reading,MA, 1978).

15. A. C. Ferrari and J. Robertson, Phys. Rev. B 63, 121405 (2001). doi:10.1103/PhysRevB.63.121405

16. J. Birrell, J. E. Gerbi, O, Auciello, J. M. Gibson, D. M Gruen and L.A. Carlisle, J. Appl. Phys. 93, 5606 (2003). doi:10.1063/1.1564880

17. W. A. Yarbrough and R. Messier, Science 247, 688 (1990). doi:10.1126/science.247.4943.688

18. J. Nemanich, J. T. Glass, G. Lucovsky and R. E. Shroder, J. Vac. Sci. Technol. A 6, 1783 (1988). doi:10.1116/1.575297

19. R. E. Shroder, R. J. Nemanich and J. T. Glass, Phys. Rev. B 41, 3738 (1990). doi:10.1103/PhysRevB.41.3738

20. R. Pfeiffer, H. Kuzmany, P. Knoll, S. Bokova, N. Salk and B. Gunther, Diamond Relat. Mater. 12, 268 (2003). doi:10.1016/S0925-9635(02)00336-9

21. S. Raina, W. P. Kang, J. L. Davidson and X. C. LeQuan, 215th ECS Meeting (2009).

22. P. Achatz, O. A. Williams, P. Bruno, D. M. Gruen, J. A. Garrido and M. Stutzmann, Phys. Rev. B 74, 155429 (2006). doi:10.1103/PhysRevB.74.155429 